\title{
The Rebirth of the IMU and ICM
}

\author{
$\mathrm{IMU}$ 의 재탄생과 ICM
}

\author{
KIM Daniel G. 김계환 KIM Sung Sook 김성숙
}

\begin{abstract}
The outbreak of the First and the Second World Wars cast great shadow across the Europe including mathematical society. The IMU led by French mathematicians after the First World War ceased to exist because it was used politically. As Europe ran into the Second World War, all the international mathematical activities were ceased. Prominent mathematicians were put into camp by Nazi or moved to the United States of America. After the war, European mathematicians did not have capacity to represent the international mathematical society anymore. This led Stone and other American mathematicians to form the new IMU, which was independent of political ideology. This paper studies the birth process of the new IMU after the War and some major events that happened to ICM in 1950s.
\end{abstract}

Keywords: IRC(International Research Council), IMU(International Mathematical Union), ICM(International Congress of Mathematicians), history of ICM, mathematics education; 국제연구협의회, 국제수학연맹, 국제수학자대회, 국제수학자대회 의 역사, 수학교육.

MSC: 01-02, 97-03 ZDM: A30

\section{1 들어가는 글}

제1차 세계대전은 유럽사회의 모든 분야에 지대한 영향을 끼쳤고 수학도 예외는 아니 었다. 1919년 7월 18일부터 28일까지 브뤼셀(Brussels)에서 연합국가들이 모여 국제연 구협의회(International Research Council, 이하 IRC)를 창설하고 학회를 개최하였을 때, 처음으로 국제수학연맹 (International Mathematical Union, IMU)를 만들기로 결 정하였다. 그 후 1920년 ICM이 시작되기 이틀 전인 1920년 9월 20일에 벨기에, 프랑 스, 이탈리아, 일본, 세르비아, 영국, 미국, 체코슬로바키아, 그리스, 포르투갈과 폴란 드에서 11 개 국가의 대표들이 스트라스부르대학에 모여서 1919년에 브뤼셀에서 결정된 국제수학연맹 창립을 재확인하여 공식적으로는 1920년 9월 20일에 국제수학연맹 (IMU) 이 창립되었다고 본다. 이 11국가 중 9국가가 제1차 세계대전에서 승리한 연합국들이

\footnotetext{
*Corresponding Author.
}

Receiveded on Oct. 13, 2012, revised on Jau. 11, 2013, accepted on Jau. 19, 2013. 
었다. IRC가 독일을 비롯한 당시의 강대국을 배제하는 정책을 계속 주장해왔기에 IMU 도 영향을 받아, 독일을 비롯한 강대국의 가입금지규정을 따랐다. 독일을 비롯한 당시의 강대국을 배제하는 정책을 계속 주장해온 IRC는 결국 많은 국가들의 반대로 1931 년에 해체되었고 순수한 목적으로 운영되지 못하고 IRC의 입김을 받았던 IMU도 결국 1932 년 수학자들에 의하여 해산되었다. 이후 1951년에 IMU가 재창조되기까지 수학연맹은 존재하지 않았다[1].

IRC가 1931년 브뤼셀에서 열렸던 제 5회 IRC 총회에서 해체된 후, IRC는 국제과학 연합회(International Council of Scientific Unions, 이하 ICSU) 로 거듭난다. 초기의 ICSU의 산하단체는 9 개의 과학연맹과 41 개의 국가가 회원이었다. ICSU는 각 산하단 체가 독립적으로 운영이 될 수 있도록 하였다. ICSU의 기본 원칙은 회원가입에 정치적 인 어떤 차별도 두지 않는 것이었기에, 비록 ICSU에 속하지 않은 국가라 할지라도 각 산하단체의 회원이 될 수 있었다.

그러나 히틀러가 1933년 정권을 잡은 후에, 독일에서 많은 변화가 일어났다. 그동안 독립적으로 운영해 오던 각 대학과 연구소들이 독일정부의 간섭을 받게 되었다. 이런 독 일의 제도로 인해 독일은 ICSU와 그 산하단체와 좋은 관계를 유지할 수가 없었다. 과 학자들이 생각했던 과학과 정치는 분리되어야 한다는 견해가 근본적으로 잘못된 것이라 고 공표되었다. 1928년에도 제 8차 ICM에 불참할 것을 독일의 모든 중고등학교와 대학 에 보내어 수학자들의 연합을 방해하였던[1] 비버바흐(Bieberbach)는 이번에도 새로운 학술지인 독일수학(Deutsche Mathematik)을 창간하고 독일의 민족주의와 반유대인의 감정을 그대로 드러내어 "아직도 유대인이 학술원에 있는 것이 놀랍다" 는 등의 글을 실 었다[8]. 그가 죽은 후에 많은 수학자들은 비버바흐가 높은 지위에 올라 독일수학자들의 리더가 되기 위하여 나치와 협력하며 유대인 수학자들을 연구소에서 추방하였다고 평 가한다[7]. 또한 1938년에 독일한림원(Prussian Academy)은 독일과학자들에게 ICSU 산하단체에서는 활동을 하되 ICSU의 회원으로 가입하지 말라고 명령하였다. 이무렵 베 르발드(Ludwig Berwald)를 비롯한 뛰어난 수학자들이 죽임을 당하거나 감옥에 가거나 숨어서 살게 되었고 나치로부터 추방명령을 받거나 자의로 다른나라로 이주한 수학자들 도 많았다[3].

1931년 취리히 (Zürich)에서 열렸던 제9차 국제수학자회의(International Congress of Mathematicians, 이하 ICM)에서 IMU를 해체하기로 결정한 후[4], 다시 새로운 IMU 를 조직하려고 노력하던 위원회는 이전의 경험으로 볼 때, 독일을 제외하고 IMU를 만 드는 것이 좋은 선택이라고 생각하지 않았고, 또한 국제적 정세를 봐도 IMU를 다시 조 직하는 것이 순조롭지 않았다. 독일만 문제가 있었던 것이 아니라 이탈리아의 무솔리니 (Mussolini)도 에티오피아를 침공하고, 스페인에서는 시민전쟁이 일어나 유럽전체에 정 
치적인 긴장이 감돌았다. 무솔리니는 이탈리아 한림원의 회원을 스스로 지명하며 과학 계에 정치적 영향을 끼쳤다. 소비에트 연방(the Soviet Union)도 제 7차부터 9차까지 의 ICM에는 참석을 하였지만 그 이후에는 참석하지 않았다. 1936년 오슬로(Oslo)에서 열렸던 ICM에서는 4년 전에 구성되었던 IMU의 재창설을 위하여 연구하던 위원회 위 원을 다시 임명하지 않았지만 어두운 정치환경 속에서도 오슬로에서 열렸던 ICM에서는 $\mathrm{IMU}$ 의 중요성과 필요성에 대한 많은 논의가 있었다[5].

1939년에서 1945년까지 일어났던 제2차 세계대전으로 말미암아 ICSU와 산하단체의 활동이 중단되었다. 전쟁 후 서방연합국과 소비에트 연방과의 협력은 오래가지 않았다. 철의 장막은 세계를 분단시켰고, 냉전이 시작되었다. 또한 식민지 시대에 힘을 가졌던 나 라들이 약화되면서, 많은 국가들이 새롭게 탄생하였다. 독일, 이태리, 일본의 연합(The Axis Powers)에 대항하기 위해 형성되었던 연합국가들의 모임인 유엔(The United Nations, 이하 UN)은 국제 평화와 안전을 유지하기 위한 새로운 국제기구로서의 역할을 하게 되었다. 수학계를 제외한 모든 과학분야의 중심이 유럽에서 북미 (North America) 로 이동하고 있었다. 유엔 산하기관인 교육, 과학, 문화 분과(The United Nations Educational, Scientific, and Cultural Organization, 이하 UNESCO)는 이러한 수학계 의 문제점을 감지하고 ICSU를 통해 해결할 방법을 강구하여 수학분야에 재정 지원을 시작하여 후에 IMU을 재탄생시키는 중요한 역할을 하였다. ICSU의 기본이념은 어느 국가도 배제하지 않는 과학의 국제화를 이루는 데 있었고, 이 원칙은 새로운 IMU가 창 설될 때와 전후 처음으로 열린 ICM에도 영향을 미쳤다. 제2차 세계대전 후의 시대는 제1차 세계대전 후와 완전히 달랐다[5].

\section{IMU의 재탄생}

1936년 오슬로에서 개최되었던 ICM의 폐회식에서 차기 ICM 개최지가 미국이라는 사 실이 발표된 후 많은 미국수학자들은 하버드대학과 MIT에서 1940년 9월 4일부터 12 일까지 ICM을 열기로 결정하고 준비하면서 등록비를 10 달러로 정하였다. ICM 대회장 은 버커프(G. D. Birkhoff)가 맡았다. 그러나 1939년 9월 1일 독일이 폴란드를 침공한 후, 곧 제2차 세계대전이 시작되어서 미국수학자들은 1939년 9월 6일에 1940년 ICM 을 개최하지 않기로 결정을 내렸다. 전쟁 중에 ICM이 국제학회가 되기에는 어렵다는 판단으로 연기한 것이다[5].

\subsection{IMU 재창설의 준비}

제2차 세계대전이 끝난 바로 직후인 1945년 여름 끝무렵부터 ICSU는 활동을 재개하기 시작하여, 전후 첫 모임을 1946년 7월 런던에서 가졌다. 이 모임에서 네덜란드 대통령 
은 "우리는 과학에서 정치를 배제하여야합니다, 왜냐하면 제1차 세계대전이후 ICSU의 전신이었던 IRC가 얼마나 이 일에 소홀히 했는지를 알기 때문입니다.”라고 연설하였다.

제2차 세계대전 후, 국제적인 수학연합회의 필요성을 느끼는 수학자들이 많아졌다. 1947년에 창간된 오스트리아(Austria) 수학학술지 (Nachrichten der mathematischen Gesellschasft in Wien)에는 “인류의 주된 목적은 전쟁이 끓었던 경제적 그리고 문화적 매듭을 다시 묶는데 있다”라는 글이 발표되었다. 이 학술지는 향후 20 년간 IMU의 공 식학술지의 역할을 하게 되었다. 같은 해인 1947년 프랑스수학회는 전후에 열리는 첫 $\mathrm{ICM}$ 에서 IMU 재창설을 위한 토대를 이루어야 한다고 제안하였다. 제2차 세계대전이 유럽에서 시작되어 유럽은 경제적으로나 정치적으로 여유가 없던 시기였기에, 1940년대 는 미국수학자들이 모든 준비를 해야만 하는 시기였다. 돌이켜보면 1936년에 차기 ICM 의 개최지로 미국이 선정된 것이 수학계로서 다행한 일이었다. 이 무렵 전 세계의 수학 자들을 다시 연합하게 만들수 있는 가장 적합한 나라가 미국이었다[5].

미국수학자들은 전쟁 후 국제적인 의무감을 떠안고 바로 행동을 취하기 시작하였다. 1939년 9월에 조직되었던 미국수학회의 비상실행위원회(the Emergency Executive Committee of the Congress)가 특별한 사명감을 갖고 일하기 시작하였다. 1945년 ICM의 조직위원 구성을 위한 토론이 시작되었을 때, 이전의 ICM 대회장을 맡았던 버커프가 1944년에 사망하자 모스(Marston Morse)가 비상실행위원회의 새 회장으로 선출되었 고 이 위원회는 1946년 4월 전국 미국수학회에서 "ICM은 모든 수학자들이 조건없이 초 청받을 때만 다시 개최한다"라고 선언하였다. 이 선언은 그 회의에서 만장일치로 통과 되었고, 삼 개월 후에 있었던 ICSU의 총회에서도 이 선언이 과학계에 있었던 정서가 반영된 결과라고 주목받았다. 미국인들의 “세계화선언(Declaration of Universality)” 은 수학발전에 중요한 의미를 부여하였고 국제수학계의 협력을 위한 초석이 되었다. 비상 실행위원회는 ICM을 1948년에 개최하기에는 너무 이르다고 보고 1950년에 하버드대 학에서 ICM의 개최를 1947년 ICSU에 신청하여 승인을 받았다[5].

제2차 세계대전 동안 미국 수학자들은 "수학전쟁정책위원회 (the War Policy Committee for Mathematics)"를 만들어 연합군이 전쟁에서 이기기 위한 여러가지 일에 가 담하였다. 수학전쟁정책위원회는 전쟁이 끝난 이후에도 존재했지만 그 이름에서 “전쟁” 이라는 단어를 삭제하고 수학정책위원회라 불렀다. 그 정책위원회의 구성원들은 미국수 학회(American Mathematical Society), 미국수학협회 (Mathematical Association of America), 기호논리학회(Association for Symbolic Logic), 수리통계연구소(Institute of Mathematical Statistics) 의 대표들로 구성되었다. 이 위원회가 IMU의 재창립의 가 능성에 대한 연구를 하게 되었다[5]. 1943년부터 1944년까지 미국수학회의 회장을 역 임했던 마샬 스톤(Marshall H. Stone)이 1946년 정책위원회의 회장을 맡았다. 그는 새 
$\mathrm{IMU}$ 를 태동시키는 선봉역할을 하였고 정책위원회의 회장으로서의 임기가 끝나 후임으 로 모스(Morse)가 회장이 된 이후에도 IMU가 재창설될 때까지 리더의 역할을 하였다. 1948년 여름에 스톤을 대표로 하여 클라인(Kline)과 모스로 구성된 삼인 소위원회가 구 성되어 1950년까지 IMU를 재창설할 책임을 떠안았다. 본질적인 문제는 모든 나라를 정치적 잣대와 상관없이 IMU에 포함시키느냐 아니면 제 1 차 세계대전 후처럼 적성국가 (연합군 관점에서)를 배제하느냐 하는 것이었다. ICM의 준비는 전적으로 미국수학자 들에게 달려있었으나, IMU의 재탄생은 다양한 국제적 호응이 필요하였다. 이 시기는 갖은 고초와 나쁜 기억으로 얽혀진 제2차 세계대전 직후여서 국제연합을 만든다는 것에 반대의 의견이 있을 수 있었다. 더구나, IMU의 회원은 수학자들이 아니라 각 국가였기 때문에 수학자들을 초월하는 정치적 상황을 배제할 수가 없었다[5].

스톤은 어느 나라도 배제하지 않는 IMU의 재창설을 전적으로 지지하고 있었지만, 만 약의 경우를 대비하여 조심스럽게 행동하였다. 그가 첫번째로 접촉한 사람들은 미 정부 에 있던 동료들과 과학행정관들이었는데, 그중의 한 사람이 ICSU의 미국대표였던 플레 밍 (John A. Fleming)이었다. 그는 1947년 대중연설에서 IMU에 대하여 "IMU는 제1 차 세계대전 후에 탄생하였지만 우리 미국수학자들은 그 조직과 어떠한 관계도 없었고, 왜 우리가 회비를 내어야 하는지조차 이해할 수가 없었습니다. 주로 프랑스수학자들이 IMU의 원동력이었고, 아마도 독일수학자들을 배제하려는 것이 그들의 주된 목적이었던 것같습니다.”라고 말하였다. 이어 플레밍은 1920 년대의 IMU와 ICM이 처했던 역사적 상황을 설명한 후 비상실행위원회가 지향하는 국제화에 대하여 다음과 같이 연설하였다. "우리 미국수학자들은 새로 생기게 될 IMU에서 독일과 일본 수학자들을 제외시키기를 원하지 않으며, 영국과 네덜란드 수학자들의 $90 \%$ 이상이 저희 의견에 찬성하고 있습니 다. 또한 과거에 IMU 창설을 위해 열심히 노력했던 프랑스수학자들이 결국은 프랑스문 화를 주변국에 심기 위한 정치적 행위를 했다는 사실에 깊히 유감을 표합니다.”

또한 스톤은 앞으로 신설될 모든 국제기구에 러시아 학자들을 포함시킬 것을 역설하 였고, 러시아 학자들이 바깥 세계와 소통할 수 없는 현실을 개탄하였다. 이러한 장벽 에 대하여 ICSU도 많은 관심을 표명하였다. ICSU 사무총장이었던 스트라톤(F. J. M. Stratton) 은 1947년 러시아 학자들을 참여시키는 문제에 관하여 다음과 같이 썼다[5]. "러시아 학자들은 천문학과 화학을 제외하고는 어떠한 국제연합회에도 계속 불참하였습 니다. 파리에서 공식적으로 러시아 학자들에게 발송했던 우리의 우려를 담은 편지들은 상당 부문 그들에게 도착하지도 않은 것으로 밝혀졌습니다. 이에 우리는 스탈린에게 직 접 편지를 보내기로 결정하였고 나 자신이 그 편지를 작성하려고 하나, 낙관적인 결과를 기대하기는 힘들다고 봅니다.”

스톤의 정책위원회는 1947년 11월 멕시코에서 열리는 UNESCO모임에서 외국 수학 
자들을 만나기 위하여 계획을 세우고 이번 UNESCO 회의기간 중에 수학자들만의 모임 을 갖기 위한 자금을 미국수학회를 통하여 ICSU에 요청했다. 그러나 이 요청은 받아들 여지지 않았고 수학자들만의 모임을 위한 계획도 무산되었다. 그 대신 결국 1950년에 열리는 ICM 기간에 연합회의(Union Conference)를 하도록 결정하였다. 돌이켜 보면 3년이라는 더 많은 준비기간을 갖게 된 좋은 기회로 평가된다[5].

\subsection{IMU의 법령}

1948년 7월에 스톤은 IMU 재창설을 위하여 적성국가의 가입허가 여부, 사무국의 위 치, 그리고 국가별 투표권 및 회비 책정에 대한 실행계획을 모스와 클라인에게 설명하 였다. 또한 연합회의의 시기와 장소에 관하여 1950년 ICM이 열리기 바로 직전 프린스 턴(Princeton)이나 뉴욕(New York)이 바람직하고 이 연합회의에서 장차 IMU의 회원 권을 관장할 실행위원회의 창설과 그에 관한 법령이 만들어져야 할 것이며, IMU는 어 떤 형식에도 구애받지 않고 이 법령과 국가들의 자발적 회원권에 기반을 두어야 한다고 제안하였다. 이 제안들은 훗날 IMU가 재창설될 때까지 정확하게 시행되었다[5].

1948 년 10월에 정책위원회가 외국 수학자들과 연락할 준비를 마치고 1950년 5월에 $\mathrm{ICM}$ 의 공식초청장을 발송하기 전까지, 이 위원의 모든 서신은 스톤이 서명하였다. 그는 $\mathrm{IMU}$ 의 재창설과정에 현격히 주도적인 역할을 하였다. 처음부터 스톤은 IMU와 관련된 문제를 처리하는데 실용적인 방법을 추구했다. 이를 반영하듯 그의 첫번째 정기서신 "통 신 1편 (Communication I)"은 매우 간단하였다. 이 편지에서 그는 정책위원회의 역할 을 제시한 후, 1950 년까지는 IMU의 기초를 쌓기 위한 대의원들로 구성된 대표회의가 생길 것이라고 썼다. 또한 그는 다음 $\mathrm{ICM}$ 의 개최지는 미국이고, 그 이전에 별도의 준비 회의를 개최하는 것이 필요하다고 언급하였고, 개최국인 미국 수학위원회가 호스트 역 할을 하여 필요한 실질적인 준비를 할 것이라고 언급하였다. 마지막으로 그는 각 나라가 수학대표 사절단을 구성하여야 한다고 촉구하였다[5].

스톤의 첫 번째 서신 “통신 1편”은 1948년 10월 28 일 아르헨티나, 브라질, 영국, 덴마 크, 프랑스, 인도, 그리고 스위스의 여러 단체 및 수학자들에게 보내졌다. 첫 번째 수신 자들의 선택 범위에 대한 논쟁이 있었지만, 수신자의 범위는 1949년 여름까지 소비에트 연방과 중국을 포함한 26 개 국가까지 단계적으로 확대되었다. 그 후 스톤은 "통신 2편 (Communication II)"를 1949년 2월21일 발송하였는데, 여기에는 수신자들을 초청하는 초대장이 포함되어 있었다. 이 편지에서 스톤은 “곧 열릴 연합회의의 성공은 여러 다른 의견들을 질서정연하게 논의하고 존중하여 조화롭게 수렴하는 데 있습니다. 서신을 통하 여 우리가 할 수 있는 만큼의 법령과 규정에 대한 초안을 만들어 효율적인 회의의 기초 를 닦을 것을 제안합니다. 이 편지의 주된 목적은 동료 수학자 여러분들의 도움으로 그 
초안을 만들 수 있도록 협력을 부탁하기 위한 것입니다.”라고 썼다. 스톤은 또한 회의 그 자체로만으로는 IMU를 창설할 수 없다고 지적하고, IMU에 가입하기 위한 국가적 혹은 지리적 집단에 대한 법령과 규정의 동의가 연합회의에서 의결되어야 한다고 강조 했다[5].

스톤은 또 다음과 같은 실질적인 제안을 했다[5].

“우리가 제일 쉽게 접근하는 방법은 적절한 모델을 찾아 그것에 근거하여 일을 시작 하는 것입니다. 제가 다른 국제 연합들의 법령을 조사한 바에 의하면 결정학 국제연합회 (International Union of Crystallography)의 법령과 규정들이 가장 훌륭한 모델이라는 결론에 도달했습니다. 저는 여러분들이 이 모델을 주의깊게 연구해서 바꾸고, 빼고, 더 해야 할 중요 사항들을 저에게 보내주시기를 부탁드립니다. 그러면 저는 의견들을 종합 하여 일치하는 점들과 일치하지 않는 부분들을 정리하여 발표하겠습니다. 우리가 토론 하는 가운데 일치점에 이를 때마다 그에 상당하는 법령과 규정들을 만들어 여러분들께 자문을 구할 것입니다. 일치점을 찾지 못하는 부분에 관하여는 대략의 초안만 만들어 1950년 연합회의에서 더 구체적으로 의논하면 될 것입니다.”

결정학 국제연합의 법령과 규정 외에도, 스톤은 그 자신이 작성한 "IMU의 목적 $(\mathrm{Ob}-$ jects of the Union)”이라는 사항을 첨부하였다. 스톤은 IMU가 매우 광범위한 능력을 가져야 하지만, 극히 제한적인 의무만을 부여하여 행동의 자유를 가져야 한다고 설명하 였다. 예를 들면, ICM과 장차 생길 IMU의 관계는 느슨하고 유연하여야 한다는 것이다. 스톤이 작성한 목적은 IMU의 첫 법령이 통과될 때까지 거의 수정되어지지 않았고 지금 까지도 거의 바뀌지 않았다. 첫 번째 법령과 2010년 법령과의 유일한 차이점은 “목적" 으로 사용한 단어가 “Objects"에서 "Objectives"로 변한 것뿐이다. 내용 자체는 처음과 변함이 없었다[5].

\section{IMU 법령}

1. 수학의 국제 협력을 위하여;

2. ICM과 다른 국제 과학 회의와 학회 지원과 보조를 위하여;

3. 순수, 응용, 혹은 교육에서 수학의 발전에 기여하는 국제 수학적 활동을 격려하고 지원하기 위하여.

\subsection{IMU의 재탄생을 위한 연합준비회의}

연합회의를 뉴욕의 콜롬비아대학에서 열기로 1949년 12월 정책위원회가 공식적으로 결 정을 내리고 며칠 후 정책위원회는 UNESCO가 참가자들의 교통비를 위하여 만 불을 보조할 것이라고 알렸다. 당시 미국을 제외한 다른 나라는 회의참가를 위한 보조금이 없었기에 이 보조금은 무척 중요하였다. 1950년 8월 27일에서 29일까지 열리는 연합회 
의의 초대장은 1950 년 5월에 정책위원회의 회장인 모스와 사무총장인 클라인 이름으로 발송되었다. UNESCO덕에 한 국가 당 한 사람씩 교통비를 보조받았다. 그러나 콜롬비 아대학 기숙사 사용료와 식비는 개인이 부담해야만 했다. 처음에 공식언어를 영어, 불 어, 독일어, 이탈리어로 하였으나 후에 독일어, 이탈리어는 통역비가 너무 비싸서 제외 시켰다[5].

이 회의에서 IMU의 재창설을 위한 많은 중요한 결정이 이루어졌고 IMU의 법령과 규 정에 대한 논의가 있은 후 채택되었다. 임시위원회에서 사무총장으로 제슨(B. Jessen) 을 선출하였다. 1950년 제슨은 IMU의 법령과 규정을 수정하여 IMU의 회원이 될 만한 수학활동이 활발한 여러 국가 기관에 뉴욕회의의 결의문와 함께 IMU의 가입서와 IMU 의 법령과 규정을 보냈다. 모든 답장은 사무총장에게 보내기로 하였고 그가 코펜하겐에 있는 왕립덴마크 과학한림원에 있었기에 첫 IMU의 임시 사무국은 코펜하겐에 있게 되 었다. 결의문의 4 항은 10 개국이 찬성하면 IMU를 창립한다는 것이었는데, 10 개국에서 찬성한다는 편지를 보내와서 1951년 9월에 IMU가 재탄생하게 되었다. 찬성한 10 개국 은 오스트리아, 덴마크, 프랑스, 독일, 영국, 그리스, 이탈리아, 일본, 네덜란드와 노르 웨이였다. 그 후 1951년 12월에 호주, 캐나다, 필란드, 페루와 미국이 IMU에 가입하였 다[5]. 재탄생된 IMU의 첫 총회는 1952년 3월 6일부터 8일까지 로마에서 열렸다.

\section{4 제 11차 ICM}

1944년에 버커프가 별세한 후 베블린(Oswald Veblen)이 미국수학회의 리더가 되었고 $\mathrm{ICM}$ 의 회장대리로 선출되었다. 1948년에 버커프의 아들인 개럿 버커프(Garrett Birkhoff) 를 조직위원회의 회장으로 클라인을 사무총장으로 선출을 하였다[5].

전쟁 후에도 냉전이 계속되었으므로 학회를 국제적으로 여는 것은 쉽지 않았다. 세 계의 수학자들이 미국 입국비자를 얻는 데 문제가 없도록 조직위원들은 많은 노력을 하 였지만[3], 소비에트 연방과 다른 공산국가에서는 아무도 참석하지 않았다. 조직위원회 총무였던 클라인은 이 사실에 대하여 다음과 같이 말하고 있다.

“철의 장막 뒤에 있는 수학자들은 정부로부터 ICM에 참석하는 것을 금지당하고 있습 니다. 그들의 정부가 여권을 만들어주지 않습니다. 그들의 불참은 미국정부와 아무 상 관이 없습니다."

정치가 다시 수학활동에 개입이 되었지만 이번에는 수학자들이 힘을 합쳐 전세계의 협력을 이끌어내려고 최선을 다한 점이 제 1 차 세계대전 후의 상황과는 근본적으로 달랐 다.

드디어 제2차 세계대전 후의 첫 ICM이 1950년 8월 30일에서 9월 6일까지 미국 캐 임브리지(Cambridge)에 있는 하버드대학에서 개최되었다. 40 개국에서 1,700 명의 수 
학자를 포함한 2,300 명이 참가하여 이전에 비하여 두배 이상의 많은 사람들이 참가하였 다. 그 중 $80 \%$ 가 미국에서 참석하였다. 이것은 미국수학자들의 힘이 상당히 커졌음을 의미한다. 1,700 명의 수학자 중 미국과 캐나다를 제외한 수학자는 290 명이었는데, 많은 수학자들이 미국에 올 경제적인 여유가 없었기 때문이었다. ICM 개회식 전에 소비에트 연방으로부터 다음과 같은 전보가 도착하여 개회식에서 낭독되었다[5].

“소비에트 연방 과학한림원은 ICM이 소비에트 연방 과학자들을 초대한 것을 고맙게 생각합니다. 소비에트 연방 수학자들은 해야할 일들이 많아 ICM에 참석할 수가 없습니 다. 이번 ICM이 수학계에 의미있는 학회가 되기를 바랍니다. 성공을 기원하며... 바빌 로브(S. Vavilov)”

소비에트 연방에서 온 친밀감있는 전보는 수학연합회의 미래에 희망을 주었다. 이 대회에서 이전의 ICM의 전통을 유지하려는 노력이 엿보였다. 특히, 세 명의 명예회장 을 보면 잘 알 수 있다. 이들 명예회장은 모두 84세가 넘은 벨기에수학자인 발레 푸생 (Charles de la Vallée Poussin), 프랑스수학자 아다마르(Jacques Hadamard)와 이탈 리아의 카스텔누오보(Guido Castelnuovo) 였다. 개회식에서 프린스턴 고등연구소의 베 블린(Oswald Veblen)이 만장일치로 ICM의 회장으로 추대되어 다음과 같은 연설을 하 였다[2].

"1936년에 차기 ICM을 미국에서 개최한다는 발표를 한 지 14 년이 경과하였습니다. 우리는 새로운 시대로 넘어가고 있습니다. 제 말은 많은 영향력있는 수학자들이 전세계 로부터 북미로 건너오셔서 미국의 수학 사상의 전통과 경향이 급속하게 바뀌며 풍부하게 된 것을 의미합니다. 이러한 미국의 이득은 유럽수학에 큰 손실이 될 것 같지만 유럽에 미치는 손실이 단지 일시적일 것이라는 많은 증거들이 있습니다. 반면에 미국이 얻은 영 향은 영원할 것입니다."

이어서 두 번째의 필즈상 수상식이 있었는데, 수상자는 프랑스 낭시(Nancy) 대학의 로 랑 슈와르츠(Laurent Schwartz)와 프린스톤 고등연구소의 아틀레 셀베르그(Atle Selberg)이었다. 필즈상 수상위원회의 의장이었던 보어(Harald Bohr)가 나와 슈와르츠와 셀베르그의 업적에 대하여 보고를 하였다.

이 대회에는 총 22 개의 기조강연이 있었고 374 개의 논문이 7 개의 분과에서 발표되었 다. 7 개의 분과는 다음과 같다[3].

제1 분과: 정수론(Number Theory)과 대수(algebra) 제2 분과: 해석학(analysis) 제3 분과: 기하학(geometry) 과 위상수학(Topology) 제 4 분과: 확률과 통계, 보험수리학, 통계학, 경제학 제 5 분과: 수리물리와 응용수학 
제6 분과: 논리학과 철학

제7 분과: 역사와 교육

이전 ICM과 비교하면 천문학이 빠졌고 1936년부터 위상수학와 경제학 분야가 새롭게 생긴 것이다. 1948 년 중반에 ICM의 알림을 보면 공식언어에 영어, 불어, 독일어, 이탈 리어와 러시아어가 포함되었다[3]. 1930년 후반에 처음으로 수학의 특정 분야에 초점을 맞춘 학회가 열렸는데, 이 학회는 매우 성공적이었다. 하나는 모스크바에서 열렸던 위 상수학 학회이고 다른 하나는 취리히에서 열렸던 확률에 관한 학회였다. 이것을 모델로 조직위원들은 ICM중에 4 개의 학회를 열었다. 4 개의 분야는 대수학, 응용수학, 해석학, 위상수학이었다. 각 학회프로그램은 초청강연과 자유로운 토론으로 구성되었다. 폐회 식에서 다음 ICM은 1954년 네덜란드에서 개최하기로 만장일치로 결정되었고 스톤은 ICM 바로 전에 뉴욕에서 열렸던 IMU의 창설을 위한 연합회의 결과를 보고하였다. 이 대회에도 참가자들이 즐길 수 있는 많은 프로그램이 있었다. 개회식날 밤에는 하버드대 학의 미술관에서 환영만찬이 있었고 금요일 저녁에는 웨슬리대학에서 티파티가 있었다. 토요일 저녁에는 두 가지 선택이 있었는데, 한 가지는 댄스파티에 참석하거나 맥주파티 에 참석하는 것이었다. 일요일에는 학회가 없었으며 음악회가 열렸다. 화요일 저녁에는 학회 만찬이 있었으며 수요일에는 환송파티가 있었다[3].

이 대회를 위해 많은 사람들이 기부를 했지만, 기부를 가장 많이 한 기관은 미국수학 회, 록펠러재단과 카네기 회사였다. 가까이에 있는 하버드대학, 보스톤대학, 예일대학, MIT, 프린스턴 고등연구소도 기부를 하였고 UNESCO는 학회 프로시딩 인쇄비를 지 원하였다[3]. 그 외에 보험회사, 화학관련회사, 자동차회사, 가스회사, 출판사, General Electric, 벨 (Bell) 전화회사, 코닥, 과일회사 등 많은 회사에서 기부를 하였다. 등록비는 10 년전에 계획했던 것보다 $50 \%$ 가 올라 15 불이었다. 기부자들의 명단은 프로시딩 앞쪽 에 자세히 기록되어 있다[6].

\section{3 마치는 글}

제 2차 세계대전 이전에는 수학을 비롯한 과학의 중심이 유럽이었고 거의 모든 국제학 회는 유럽에서 개최되었다. 그러나 나치가 독일에서 힘을 얻게 되자 수학자 중에서도 나치와 협력하여 개인의 영광을 얻으려는 사람들이 나타나면서 많은 뛰어난 수학자들이 죽거나, 수용소에 가거나, 미국으로 건너가게 되었다. 이로 인해 유럽에 학문적으로 많 은 손실이 있게 되어 학문의 중심이 유럽에서 미국으로 바뀌게 되었다. 이 중심에 비버 바흐가 있었는데, 그는 초기에는 동료 유대인 수학자를 두둔하다가 돌연히 나치와 협력 했을 뿐만 아니라 주도적으로 독일 민족주의와 반유대정서를 수학잡지에 기고할 정도로 
정치적이었다. 일반적으로 비버바흐는 뛰어난 수학자로서 평가를 받고 있지만, 인간적 으로 정직하지 못한 삶을 살았음을 여러 문서에서 볼 수 있다. 그가 죽고 난 후에 그에 대하여 쓴 글을 보면 그는 혼란기를 틈타서 나치와 협력하여 독일수학자들의 리더가 되 고 싶어했음을 분명하게 알 수 있다.

또한 제 1 차 세계대전 이후에 IMU를 창설하고 독일을 비롯한 당시의 강대국 수학자 들을 배제하는 정책을 폈던 프랑스수학자의 행동도 정직하지 않은 학자의 모습을 보여 준다. 그러나 제 2 차 세계대전 후에 미국이 주축이 돼서 IMU의 재창설과 ICM의 개최 를 준비하면서 과거의 프랑스수학자들의 실수를 반복하지 않고 세계 모든 수학자들을 표용하려고 하였던 것이 현명한 판단이었다고 생각된다. 비록 세계적으로 정치가 수학 계와 학자들의 삶에 많은 영향을 준 시기였지만 수학자들의 노력으로 이 모든 어려움을 극복하고 어떤 나라도 배제하지 않고 IMU를 재창설하여 수학자들이 다시 하나가 되게 한 것이 훌륭했음을 역사는 증언하고 있다. 국제수학연합회가 정치를 뛰어넘어 승리한 것이다.

스톤이 시간과 노력을 바쳐서 정성스레 준비하고 지휘하면서 만든 IMU 법령이 지 금까지도 그대로 내려오고 있다. 앞으로도 후세에 전달되며 역사에 길이 남을 것이다. 2014년 대한민국 수도 서울에서 열리는 ICM에서 우리는 이전과는 비교할 수 없을 정도 로 많은 개발도상국 수학자들이 참석하도록 지원하려고 한다. 원조를 받던 나라가 이제

는 원조를 하는 나라로 성장하였기에 그 동안 우리를 도왔던 은혜를 갚으면서 개발도상 국의 수학적 발전을 염원하기 때문이다. ICM이 역사에 아름답게 기록되는 멋진 학회가 되기 위하여 우리 모두가 협력하고 동참하기를 바라면서 이 논문을 맺는다.

\section{참고 문헌}

1. 김성숙, 강미경, ' $\mathrm{IMU}$ 탄생에서 해체까지의 $\mathrm{ICM}_{\lrcorner}$, 한국수학사학회지 25(3), pp. 1-12.

2. Albers, D. J., Alexanderson, G. l., Rei, C., International Mathematical Congress, Springer-Verlag, 1987.

3. Curbera G., Mathematicians of the World, Unite!: The International Congress of Mathematicians: A Human Endeavor, CRC Press, 2009.

4. Curbera.G., "ICM through history", Newsletter of the European Mathematical Society, No. 63, 2007, pp. 16-21.

5. Lehto, O., Mathematics without Borders: A history of the International Mathematical Union, Springer- Verlag, New York, 1998.

6. Graves, L., Smith, P., Hille, E., Zariski, O., Proceedings of The International Congress of Mathematicians, American Mathematical Society, 1952.

7. Huckle, T., "Mathematicians during the Third Reich and World War II," <http:// wwwenger.informatik.tu-muenchen.de/ huckle/mathwar.html>. 
8. O’Connor, J. J., Robertson E.F., "Ludwig Georg Elias Moses Bieberbach," <http:// www-history.mcs.st-andrews.ac.uk/Biographies/Bieberbach.html>

KIm Daniel G.

Department of Mathematics, Southern Oregon University

E-mail: kimd@sou.edu

KIM Sung Sook

Department of Applied Mathematics, Paichai University

E-mail: sskim@pcu.ac.kr 


\section{ABSTRACTS}

LeE Chang Koo, Hong Sung Sa 이창구, 홍성사 Chinese Mathematics in Chosun 『朝 鮮과 中國 數學』

중국 수학을 토대로 조선 수학이 발전된 것은 잘 알려져 있다. 이 논문에서는 조선에 유입된 중국 산서의 역사를 조사하여 중국 수학이 조선 수학에 끼친 영향을 연구한다. 15 세기 世눅대에 들어온 중국 수학, 17 세기 서양 수학의 영향을 받은 중국 수학과 19세기 중국에서 재정리된 송, 원대의 수학으로 나누어 이들이 유입되는 과정도 함께 조사한다.

\section{Morimoto Mitsuo Three Authors of the Taisei Sankei}

The Taisei Sankei(大成算経 in Japanese) or the Dacheng Suanjing(in Chinese) is a book of mathematics written by Seki Takakazu 関孝和, Takebe Kataakira 建部賢明 and Takebe Katahiro 建部賢弘. The title can be rendered into English as the Great Accomplishment of Mathematics. This book can be considered as one of the main achievements of the Japanese traditional mathematics, wasan, of the early 18th century. The compilation took 28 years, started in 1683 and completed in 1711. The aim of the book was to expose systematically all the mathematics known to them together with their own mathematics. It is a monumental book of wasan of the Edo Period (1603-1868). The book is of 20 volumes with front matter called Introduction and altogether has about 900 sheets. It was written in classical Chinese, which was a formal and academic language in feudal Japan. In this lecture we would like to introduce the wasan as expressed in the Taisei Sankei and three authors of the book. The plan of the paper is as follows: first, the Japanese mathematics in the Edo Period was stemmed from Chinese mathematics, e.g., the Introduction to Mathematics (1299); second, three eminent mathematicians were named as the authors of the Taisei Sankei according to the Biography of the Takebe Family; third, contents of the book showed the variety of mathematics which they considered important; fourth, the book was not printed but several manuscripts have been made and conserved in Japanese libraries; and finally, we show a tentative translation of parts of the text into English to show the organization of the encyclopedic book.

KIM Daniel G., KIM Sung Sook 김계환, 김성숙 $\quad$ The Rebirth of the IMU and ICM ${ }^{\circledR} \mathrm{IMU}$ 의 재탄생과 $\mathrm{ICM}_{\Perp}$

20 세기 초에 발생하였던 제 1,2 차 세계대전들은 유럽 사회뿐만 아니라, 수학계에도 지대한 손실을 끼쳤다. 1 차 세계대전 이후 프랑스를 중심으로 탄생되었던 국제 수학연맹 (IMU) 은 정치적으로 이용 되었던 이유로 해체되어졌고, 제 2차 세계대전이 발생함에 따라 모든 국제 학회모임은 중단되었다. 독일에 나치정권이 들어선 후, 많은 뛰어난 수학자들이 수용소에서 죽음을 맞거나 미국으로 이주하면서 학문의 중심은 유럽에서 미국으로 이동하였다. 전쟁이 끝난 후 심각한 정치 경제 위기에 처한 유럽의 
학자들은 수학계를 대변할 능력을 잃었다. 이에 국제적인 의무감을 갖게 된 미국의 스톤(Stone)을 비롯한 수학자들은 정치에 상관없이 모든 나라가 가입할 수 있는 새 IMU를 탄생시킨다. 이 논문은 제2 차 세계대전 이후에 IMU의 재탄생 과정과 1950년도의 ICM에서 일어난 일들을 면밀히 알아봄으로써 20세기 중반의 수학계의 발전상을 연구하고자 한다.

Sun Bo Euk 서보억, A Historical Process Analysis and Extension of Division into Equal Parts in Middle School Geometry 『중학교 기하영역 등분할 개념에 대한 수학사적 분석 및 확장에 대한 연굴

본 연구에서는 중학교 기하영역에서 다루어지는 등분할 개념을 조사하고, 이를 바탕으로 수학사적 분석을 통해 등분할 개념에 대한 확장 가능성을 탐구한 문헌연구이다. 중학교 기하영역에 대한 조사를 통해 선분의 등분할, 각의 등분할, 호의 등분할, 넓이의 등분할 개념이 다루어지고 있음을 발견하였다. 이들 네 개의 등분할 개념에 대한 수학사적 분석을 통해 역사적으로 등분할 개념이 다양한 측면에서 다루어졌음을 확인할 수 있었다. 최종적으로 선분의 등분할 개념과 각(호)의 등분할 개념은 방법적 측면에서의 확장에 대해 고찰하였고, 넓이의 등분할 개념은 개념적 측면에서의 확장에 대해 탐색하였 다. 본 연구에서 제시한 등분할에 대한 수학사적 분석 및 확장에 대한 분석 결과를 통해 중등학교에서 수학사의 효과적 활용에 대한 방향 설정이 기대된다.

JANG Yun Sun, KIm Sung Joon 장윤선, 김성준 A Study on the Usage of Mathematics Notes in Elementary School Classes 『수학노트 활용 사례에 대한 조사 연구』

본 연구는 학교수학과 수학적 의사소통을 연계하기 위한 방안으로 초등학교 현장교사들이 수업에서 사용하고 있는 수학노트의 활용 사례를 살펴본다. 수학적 의사소통은 말하기, 듣기, 읽기 활동까지를 포괄하지만 여기서는 수학적 쓰기 활동, 특히 수학노트의 활용과 관련된 목적과 필요성, 유형 등에 대해 알아본다. 이를 위해 교사들과의 면담과 서술형 설문지를 통해 수학노트의 사용 이유, 수학노트에 담을 내용, 수학노트 사용에 따른 변화 등에 대한 교사들의 전반적 인식을 살펴본다. 본 연구는 교사들에게 수학적 사고력 또는 계산 능력의 신장을 포함한 수학노트의 활용 효과와 그에 대한 정보 제공 및 수학 노트 사용을 위한 기초자료의 제시를 목적으로 한다.

PARK SunYong 박선용, A Historical Analysis of Barrow's Theorem and Its Educational Implication ${ }^{\circledR}$ Barrow 정리의 수학사적 분석과 그에 따른 교육적 시사점에 대한 연 구』

이 연구에서는 수학사에 대한 해석학적 관점에서 Barrow 정리의 특징에 대해 분석하고, 현대적인 역사발생적 원리에 기초해 수학적 재발명 활동을 이끄는 미적분학 교수-학습 계열에 대해 논의한다. Barrow 정리에 대한 수학사적 분석을 통해서는, 그 정리의 기하학적 특성을 드러내고, 그 정리를 다룬 Barrow 의 의도에 대해 추측하고, Barrow 가 겪은 인식론적 장애에 대해 고찰하였다. 그리고 이러한 분석을 바탕으로 하여, 학생들이 '적분’ 과 ‘미분의 역' 이 같다는 것을 인식하도록 하기 위한 목적 지 향적이고 의미 지향적 교수-학습을 제안하고 현재 학교수학 미적분학에서 보완해야 할 사항에 대해 지적하였다.

KIm Chang Il, LeE Bong Ju 김창일, 이봉주 Mathematics Classroom in Departmentalized Classroom System: What are Required for Effective Establishment 『수학과 교과 교실의 효율적인 환경 구성과 운영을 위한 방향 탐색』 